\title{
Entre sete colinas: histórias e memórias na configuração do patrimônio de Uberaba
}

\section{Between seven hills: histories and memories in the heritage configuration of Uberaba}

\author{
Sandra Mara Dantas*
}

\begin{abstract}
Resumo
Uberaba, no Triângulo Mineiro, emancipou-se na primeira metade do século XIX e adquiriu na segunda metade desse século, notoriedade em toda a região, polarizando as demais cidades e vilas. Pessoas de diferentes procedências afluíram à cidade que também teve sua paisagem urbana transformada com construções em estilo neoclássico, instalação de equipamentos de infraestrutura, expansão do sítio original, criação de normas de conduta e movimentação de capitais. É notório que na região central constituiu-se uma série de práticas (sociais, econômicas, culturais, escolares, religiosas) e sentidos e estes, por sua vez, foram diferentemente apropriados ao longo do tempo. Atualmente, essa área é reconhecida como de grande valor histórico e cultural pois para parte dos moradores, guarda memórias que definem aspectos de sua identidade e revela alguns dos modos que a cidade foi se transformando e incorporando/rejeitando novidades.
\end{abstract}

Palavras-chave: História e Memória, Patrimônio Histórico, Uberaba

\begin{abstract}
Uberaba, located in the region called "Triângulo Mineiro", was emancipated in the first half of the Nineteenth Century and, has been known, since then, as a major regional center, competing with other cities and towns. People from different places in Brazil went to this city which had its urban landscape transformed by neoclassical style buildings, infrastructure equipment installation, expansion of the original site, creation of codes of conduct and movement of capital. It is notorious that in the central region various social, economic, cultural, educacional, religious practices which were appropriated in different ways over time. Currently, this area is recognized as of great historical and cultural value because it keeps memories that define aspects
\end{abstract}

\footnotetext{
* Doutora em História Social pela Unesp/Franca. Professora do Departamento de História da Universidade Federal do Triângulo Mineiro. E-mail: sandra.dantas@netsite.com.br
} 
of its identity and it reveals some of the ways that the city was transforming itself and incorporating or rejecting new practices.

Keywords: History and Memory, Historical Heritage, Uberaba

A memória, onde cresce a história, que por sua vez a alimenta, procura salvar o passado para servir o presente e o futuro. Devemos trabalhar de forma a que a memória coletiva sirva para a libertação e não para a servidão dos homens.

(LE GOFF, Jacques. 1994)

Segundo a versão mais aceita, os geralistas, vindos da região do Vale do Paraopeba, ao norte da província, chegaram às terras do oeste de Minas Gerais no início do século XIX, quando iniciaram a ocupação do que viria ser chamado de Sertão da Farinha Podre. Nessas terras, alguns arraiais foram criados e um deles cresceu em número de população, atividades produtivas e movimentação comercial, contribuindo com sua emancipação política.

Em um terreno de topografia acidentada, desenvolveu-se Santo Antonio de Uberaba, arraial próximo da estrada geral que levava aventureiros à província de Goiás, à procura de ouro. Poucas construções em meio à paisagem típica de cerrado - relevo acidentado, exuberantes fauna e flora, abundância de aguadas - e do alto das colinas em direção ao Córrego das Lages, ia se configurando um cenário promissor. A proximidade dos caminhos que levavam a diferentes destinos contribuiu para o afluxo de pessoas que foram adensando o arraial e, por volta de 1840, é possível afirmar que o urbano existia naquelas paragens.

Inicialmente, o sargento-mor Antônio Eustáquio Silva e Oliveira chegou às terras com sua parentela e escravos. Após demarcar a terra e iniciar a construção de uma capela e de sua chácara, incentivou que outros familiares também se mudassem para a região para engrossarem o nascente arraial e investirem naquela porção de território. Aos poucos, à atividade agropecuária foi acrescentado o comércio de produtos que circulavam pelas estradas que cortavam o arraial. Outrossim, a criação do porto às margens do Rio Grande, na divisa com São Paulo, contribuiu para que se tornasse o principal - e mais movimentado - núcleo populacional de toda a região.

A emancipação política ocorreu em 1856 quando as atividades já se diversificavam, a vida de seus moradores ia se tornando mais movimentada e os contatos com outras regiões mais freqüentes, ao ponto de a cidade 
se tornar uma espécie de entreposto para a comercialização de gêneros com Goiás, São Paulo e Mato Grosso. A cidade tornou-se um dos principais centros urbanos do oeste brasileiro, comparável a Cuiabá, dada sua movimentação e sua população que ultrapassava numericamente outras capitais como Goiás, Curitiba e Vitória. ${ }^{1}$ Outrossim, a eclosão da Guerra do Paraguai bloqueou o rio da Prata, de modo que o acesso à província de Mato Grosso passou a ser feito por Uberaba, transformada em ponto de abastecimento, o que ampliou a movimentação e as expectativas de seus habitantes.

No núcleo urbano de Uberaba uma série de novas construções e serviços passou a integrar a paisagem: arquitetura de estilo europeu, abertura de novas ruas, arborização de praças, hotéis, lojas de armarinhos, livraria, colégios, criação de um instituto politécnico, confeitaria e restaurantes com "menus à francesa", casas de jogos, associações artísticas e musicais, a realização de saraus e concertos. O ufanismo atingiu dimensões consideráveis a ponto de forjar a expressão "Paris - Rio de Janeiro - Uberaba" como exemplaridade da condição que alcançara como centro de negócios e centro sociocultural. Entre os anos 1870 a 1910, a cidade alcançou seu apogeu e, para uma parcela de seus habitantes, enfatiza a historiadora Eliane Marquez:

Freqüentar Uberaba [significava] tomar um 'banho de civilização', os avanços no desenvolvimento urbano comercial evidenciavam uma aparência de progresso e modernização, demonstravam falsamente que a cultura e os recursos importados eram fontes de autonomia cultural, econômica e política. ${ }^{2}$

A aparência de modernidade pode ser, em parte, creditada à entrada de imigrantes europeus que, provavelmente, atraídos pelas perspectivas visualizadas em Uberaba como centro econômico, influíram diretamente na alteração dos hábitos locais. A historiadora Heladir Silva assevera que nesse período a região recebeu intenso fluxo imigratório sendo que a maior parte dos imigrantes era oriunda de São Paulo. ${ }^{3}$ Dentre as nacionalidades, os italianos constituem a maior leva de imigrantes que se fixou em Uberaba, onde exerceram atividades diversificadas. A presença dos imigrantes na vida eco-

\footnotetext{
${ }^{1}$ Uberaba possuía população estimada em 7.600 hab.; Goiás, 4.500 hab.; Curitiba, 3.000 hab.; Vitória, 5.000 hab. ARRUDA, Gilmar. Cidade e sertões. Entre a história e a memória. Bauru: Edusc, 2000.

${ }^{2}$ REZENDE, Eliane M. M. Uberaba: uma trajetória sócio-econômica (1811-1910). Goiânia: ICHL/UFG, 1983 (Mestrado em História), p. 96-97.

${ }^{3}$ SILVA, Heladir Josefina S. Representação e vestígio da (des)vinculação do Triângulo Mineiro: um estudo da imigração italiana em Uberaba, Sacramento e Conquista (1890 - 1920). Franca: UNESP/FHDSS, 1998 (Dissertação de Mestrado).
} 
nômica e social da cidade foi considerável. Na imprensa havia anúncios e textos escritos em italiano, sociedades de ajuda mútua, ${ }^{4}$ eventos culturais característicos com participação da sociedade local. No aspecto econômico, pequenas indústrias de produtos típicos, transações comerciais foram marcas dessa influente presença. Muitos desses imigrantes ascenderam-se socialmente, ao passo que a maioria permaneceu como força de trabalho.

A inauguração da estrada de ferro, em 1889, fortaleceu a liderança de Uberaba na região e, como aponta a historiadora Eliane Rezende: "acelerou o processo de urbanização, promovendo o apogeu comercial e provocou a estagnação de outros centros". ${ }^{5} \mathrm{Na}$ cidade já existiam símbolos do processo de urbanização e modernização: casas comissárias; fábricas de vinho, cerveja e tecidos de algodão; agência bancária; publicação e circulação de jornais e periódicos; teatro com apresentações de espetáculos; folguedos de carnaval. No entanto, contraditoriamente após a chegada da ferrovia que alavancou a importância econômica e política de Uberaba, a mesma ferrovia contribuiu para sua estagnação, quando, seis anos depois, foram inaugurados os trilhos da Mogiana em Uberabinha (atual Uberlândia) e em Araguari. Uberaba, que figurara como área de convergência e passagem para Goiás e Mato Grosso, viu deslocar para Araguari o fim da linha férrea e pela maior proximidade dessa cidade com a fronteira goiana, logo parte do fluxo que antes se destinava a ela, foi para lá desviado.

A inflexão da economia local foi enfrentada com o investimento na agricultura e na atividade pastoril, representado pelo gado zebu, importado da Índia. A introdução da pecuária zebuína reanimou as esperanças de soerguimento da economia. $\mathrm{O}$ aumento do número de importações, o aprimoramento do plantel que se adaptou às condições climáticas da região, as exposições agropecuárias engendraram riquezas para muitos e reacendeu o surto de urbanização. O historiador Augusto Rischiteli ${ }^{6}$ sugere que a indústria zebuína acentuou o processo de urbanização em desenvolvimento desde a chegada da ferrovia. A constatação do autor é compartilhada por Heliana Salgueiro que, ao caracterizar a evolução da arquitetura, observa que com o fomento econômico da indústria zebuína, as construções se requintaram,

\footnotetext{
${ }^{4}$ As associações de apoio e sociabilidades existentes eram Fratelanza Italiana, Unitá Italiana Francesco Carrara, Associação da Beneficência Portuguesa, Sociedade Espanhola de Socorros Mútuos.

${ }^{5}$ REZENDE, Eliane M. M. Uberaba: uma trajetória sócio-econômica, op. cit. p. 21.

${ }^{6}$ RISCHITELI, Augusto B. S. P. Imagens e vozes do Sertão da Farinha Podre na produção historiográfica de Antonio Borges Sampaio. (1880 - 1908). Franca: FHDSS/Unesp, 2005. (Dissertação de Mestrado em História Social). p. 81.
} 
chegando ao apogeu nos anos 1920, quando a peste bovina encerrou as importações de gado, interrompendo o comércio e iniciando uma nova fase de crise econômica.? Tanto na zona rural quanto na zona urbana, palacetes e "bungalows" foram construídos para não só demonstrar o poderio econômico de seu proprietário, mas também para sinalizar o apuro civilizacional que, acreditava-se, ia constituindo na cidade.

Após o apogeu da exploração do gabo zebu, a economia local voltou a enfrentar obstáculos como o decrescimento da urbanização, aumento da concentração de riquezas e retraimento da imagem da cidade na região. De modo descontínuo e parcial, o processo de modernização, urbanização e civilização, iniciados no último quartel do século XIX, não fincou raízes na sociedade local. As transformações afetaram a vida e os costumes das pessoas, não obstante de modo superficial, porque tão logo os elementos da modernidade sofressem reveses, essas pessoas não recearam em retomar as antigas práticas. O desenvolvimento concentrou-se no núcleo urbano, fora dele, a dinâmica do mundo rural predominava, e, não raramente, vigorava também entre os citadinos. A construção dos palacetes e "bungalows", ao mesmo tempo, que conferia maior elegância e aparência de civilidade, na esfera dos grupos sociais de menor poder aquisitivo, a urbe estava distante de ser atingida.

Comumente, a cidade de Uberaba é chamada de "cidade das sete colinas", pois seu relevo se caracteriza pela existência de alguns aclives, denominados altos, sendo que alguns, precisamente sete, são destacados: Alto de Cuiabá, Alto da Matriz, Alto do Barro Preto, Alto da Misericórdia, Alto dos Estados Unidos, Alto da Estação, Alto do Fabrício8. E no último quartel do século XIX e primeiro do XX, uma área da cidade, constituída pelos Altos da Matriz e dos Estados Unidos, consolidou-se como a principal área histórica, pois nela se desenrolou uma série de práticas sociais, comerciais, religiosas, escolares, políticas e outras e onde teria se desenrolado os principais eventos históricos. A área inicialmente, dividida pelo Córrego da Lages, é assim descrita: de um lado a Praça Ruy Barbosa e suas adjacências e, de outro, o Largo do Rosário. Tamanha é a importância atribuída a região que as imagens mais conhecidas da cidade enfocam-na, bem como suas transformações.

\footnotetext{
${ }^{7}$ SALGUEIRO, Heliana Angotti. "Apontamentos para um estudo de arquitetura regional: ecletismo do zebu em Uberaba.” Estudos. Goiânia: UCG, 1984. Vol.11, n³/4, pp. 207-224.

${ }^{8}$ Das aglomerações populacionais desses altos surgiram, respectivamente, os bairros Mercês, São Benedito, Leblon, Abadia, Estados Unidos, Boa Vista e Fabrício.
} 
Na Praça Rui Barbosa está construída a Igreja Matriz Sagrado Coração de Jesus, onde, na primeira metade do século XX, ocorriam as principais (e mais concorridas) celebrações e festividades da cidade. E em seu entorno estavam não somente as construções mais luxuosas (os palacetes e os "bungalows") das famílias mais ricas, também as principais casas comerciais e prédios públicos como a Câmara de Vereadores.

Fotografia 1 - Vista da Igreja Matriz para o centro da Praça Rui Barbosa. Uberaba, 1906

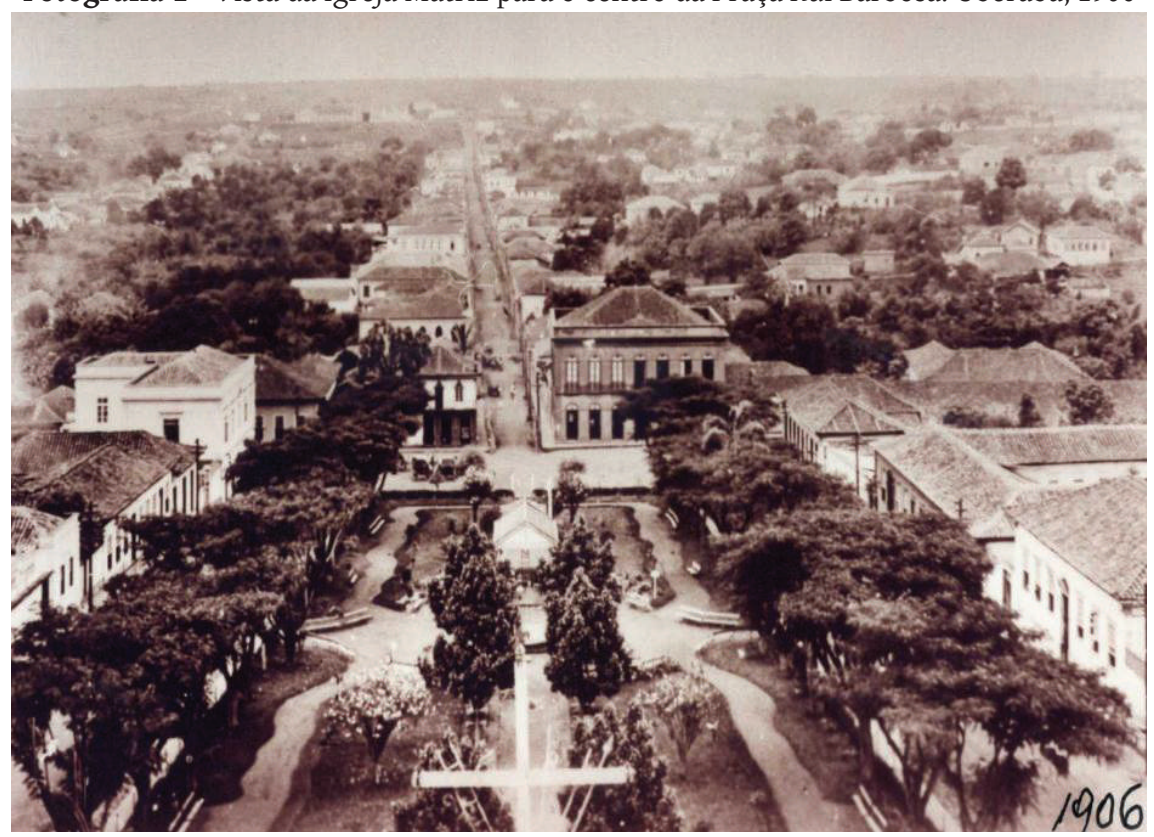

Fonte: Arquivo Público de Uberaba (APU)

Do outro lado do Córrego das Lages, a Rua do Comércio que, levava à estação Mogiana, a Igreja do Rosário e em suas adjacências, a Praça Comendador Quintino onde foi construído o Grupo Escolar Brasil e outros prédios comerciais e de serviços. Nessa porção da cidade residia a maior parte da população de baixo poder aquisitivo e a população imigrante.

A Praça Rui Barbosa foi alvo de inúmeras remodelações ao longo do século XX. A cada década, é possível identificar modificações em seu centro e no entorno. Primeiramente, era o jardim público que foi cercado para evitar depredação, em seguida, transformado em praça com plantio de mudas arbóreas, colocação de bancos e ajardinamento. A pequena igreja matriz 
de aspecto colonial, do século XIX, com duas torres laterais, foi substituída pela construção de estilo neoclássico com uma imponente torre central. Quando as árvores estavam frondosas foram arrancadas e a praça adquiriu um aspecto desolado (1916). Alguns anos mais tarde, foram plantadas inúmeras mudas de palmeira imperial que dominaram a paisagem até a década de 1940. Os palacetes e casarões em seu entorno atestavam a riqueza de seus proprietários com requintado cuidado nos detalhes arquitetônicos vistos nas janelas, alpendres, balaustres e telhado. As casas comerciais, como o concorrido $\mathrm{Au}$ bon marche, vendiam luxuosas mercadorias importadas e eram freqüentadas por "gente elegante". Por outro lado, nessas casas comerciais, não raras vezes, as mercadorias chegavam em carros de bois ou cavalos e em uma ruidosa movimentação de pessoas e animais, lembravam negociação em um arraial sertanejo ou periferia. De frente à praça, a Câmara de Vereadores onde aconteciam acirradas discussões que definiam os rumos da cidade e de seus moradores.

Fotografia 2: Largo da Matriz e Jardim Público, Uberaba, 1890.

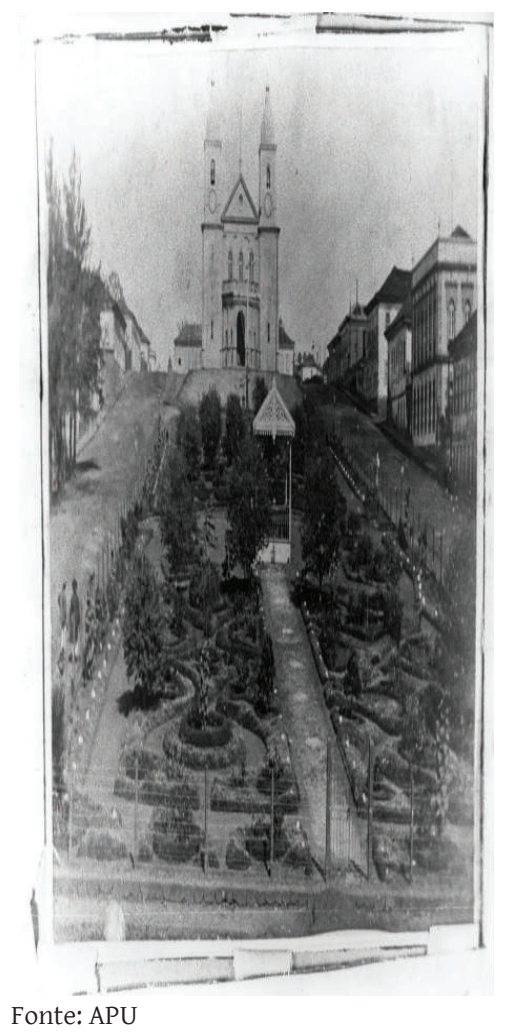


Fotografia 3: Praça Rui Barbosa. Ao fundo Rua do Comércio. Uberaba, Década 1930.

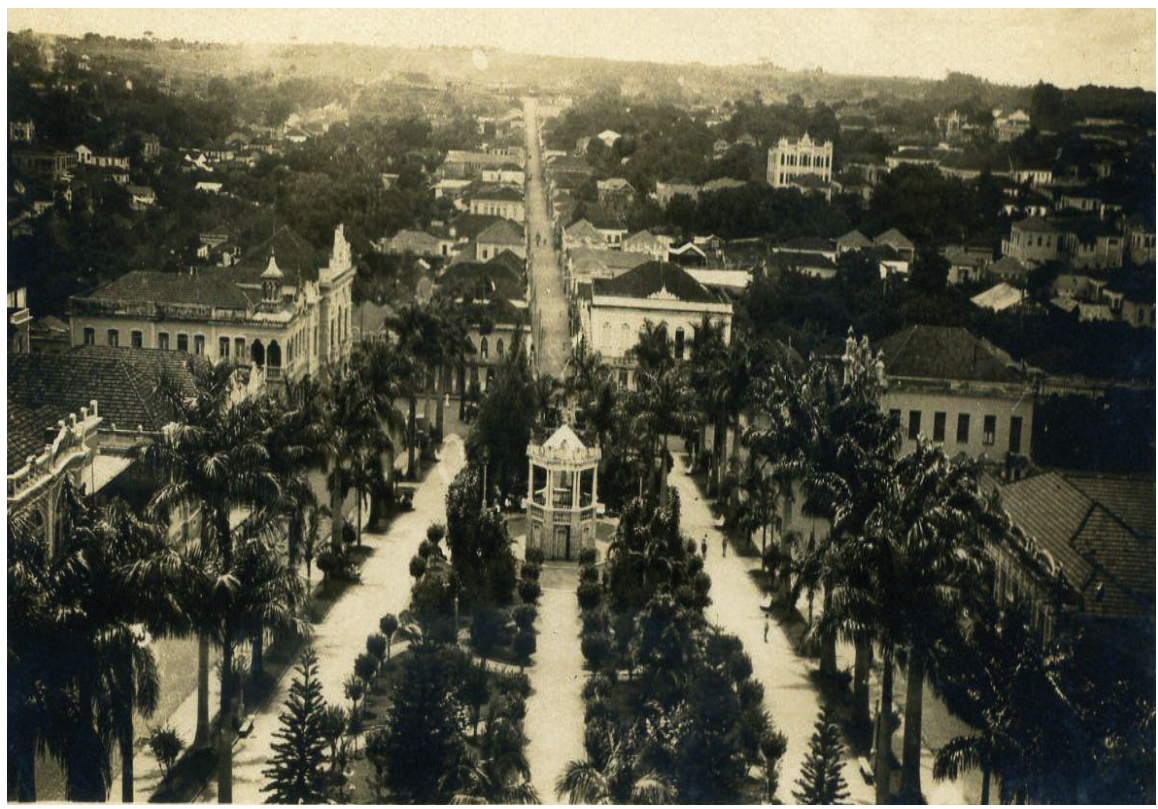

Fonte: APU

Do outro lado do córrego, a Rua do Comércio, ampla e dominada pelas casas comerciais de diversos portes e comercializando diferentes gêneros. Destaque para os comerciantes de ascendência árabe ou italiana que negociavam diferentes produtos e recebiam seus clientes em seus estabelecimentos. Prosseguindo, no alto da colina, ponto final da Rua do Comércio, a estação ferroviária da Companhia Mogiana. Geralmente, ao chegar à cidade, pessoas e mercadorias desciam a colina em direção ao centro, isto é, nesse percurso, a movimentada rua funcionava como uma espécie de mostra do que havia em Uberaba. No quinto quarteirão da Rua do Comércio, destaque para um suave aclive, onde foi construída a Igreja do Rosário que recebia, principalmente, a população negra para suas celebrações. Porém na década de 1920, a igreja foi demolida e, décadas depois, em seu lugar, aberta a Avenida Getúlio Vargas. Seguindo por ela, no alto do aclive, a Praça Comendador Quintino, em cujo centro foi construído o primeiro grupo escolar público de Uberaba, o Grupo Brasil. No entorno da praça foram construídos o prédio do Cine Teatro Royal, primeiro cinema fora do lado rico da cidade, o Hospital de Beneficência Portuguesa, casas comerciais e algumas residências de imigrantes ricos. 
Fotografia 4 - Largo do Rosário, aclive de acesso a Praça Comendador Quintino. Uberaba, Década 1940

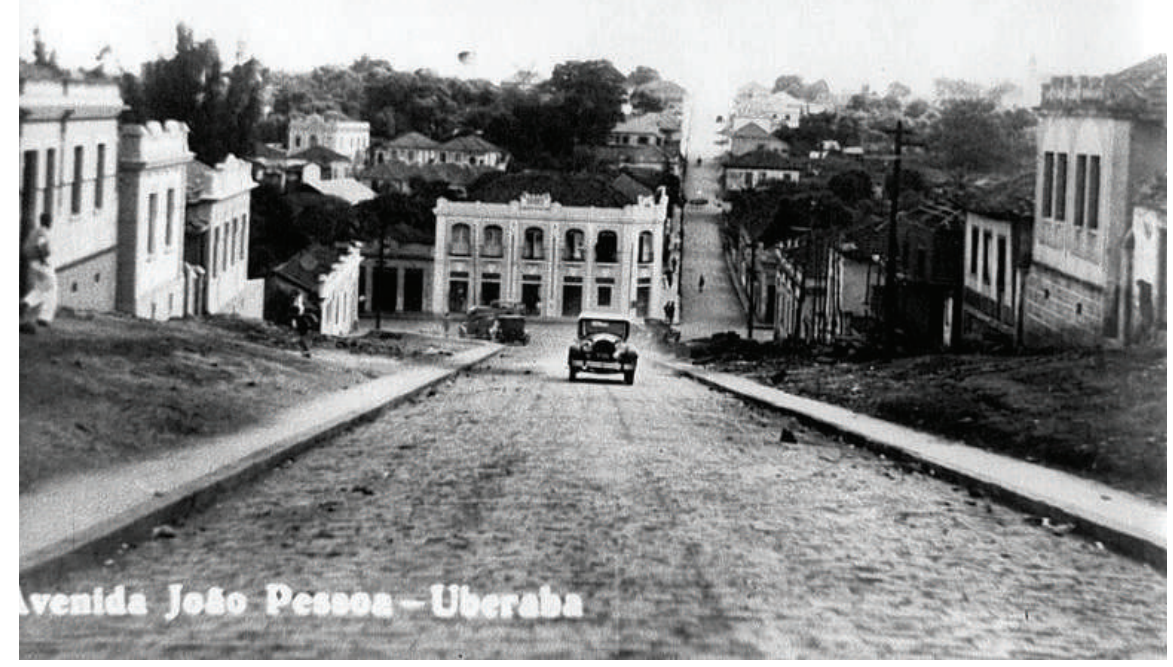

Fonte: APU

O Córrego da Lages funcionou, por longos anos, como divisor da cidade. De um lado residiam aqueles de maior poder aquisitivo e de outro, os imigrantes e os nativos de menor renda. Com sua nascente na porção norte da cidade, o curso do córrego atravessava todo o perímetro urbano, sendo utilizado para diversos fins. Na parte alta, abastecia as chácaras e servia como lazer para crianças e adolescentes. Na porção mais plana, nas imediações da região central, acumulava lixo e alguns arriscavam um pescado. Foram construídas várias pontes para que os moradores tivessem acesso à outra margem e pudessem circular pelas duas regiões. No início da década de 1930, o agente executivo decidiu pela canalização do córrego como medida de higiene e conter as enchentes que durante o período de chuvas (setembro a março), fazia transbordar o leito do córrego e inundava a cidade, arrastando tudo que estivesse em suas proximidades.

Com a canalização, cercando o leito do córrego, foi construída uma avenida, chamada Leopoldino de Oliveira (homenagem a um agente 
executivo - 1938), e que se tornou referência porque atravessa a cidade nos sentidos norte a sul. Na década de 1970, os problemas de trânsito e as recorrentes enchentes levaram a definição pela canalização fechada do córrego, aumentando as faixas de circulação da avenida. Atualmente, a Avenida Leopoldino de Oliveira é uma das principais vias de acesso entre as regiões da cidade e o Córrego das Lages que corre sob a estrutura asfáltica, vez ou outra, por causa das chuvas, transborda causando inúmeros transtornos.

Fotografia 5 - Avenida Leopoldino de Oliveira, Uberaba, 1940.

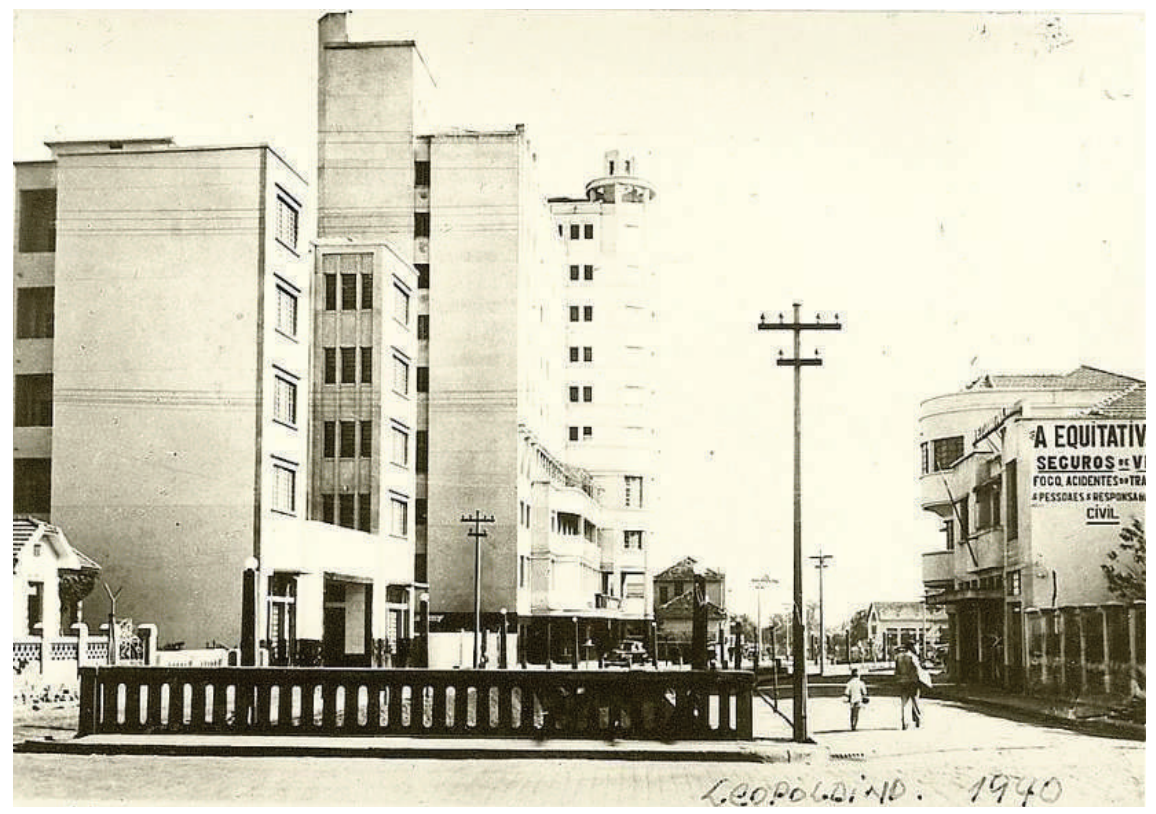

Fonte: APU

Ao longo da Avenida Leopoldino de Oliveira/Córrego das Lages também podemos identificar alguns pontos reconhecidos como de importância histórica. A Praça Manoel Terra onde estão localizados a Igreja Santa Rita, hoje Museu de Arte Sacra; o Mercado Municipal, o prédio da antiga penitenciária, atual Campus I da Universidade Federal do Triângulo Mineiro; o colégio das irmãs dominicanas, e, nele, a capela de Nossa Senhora das Dores. A cerca de duzentos metros do Museu de Arte Sacra, a Igreja São 
Domingos, construída em pedra tapiocanga e que pode ser vista de vários pontos da cidade. ${ }^{9}$

Fotografia 6 - Vista da Praça Manoel Terra e adjacências: à esquerda, Igreja Santa Rita, Torre da Capela Nossa Senhora das Dores e fachada do Colégio das irmãs dominicanas (ao fundo); à direita, Mercado Municipal (formato octogonal) e Penitenciária (ao fundo). Uberaba, Década 1920

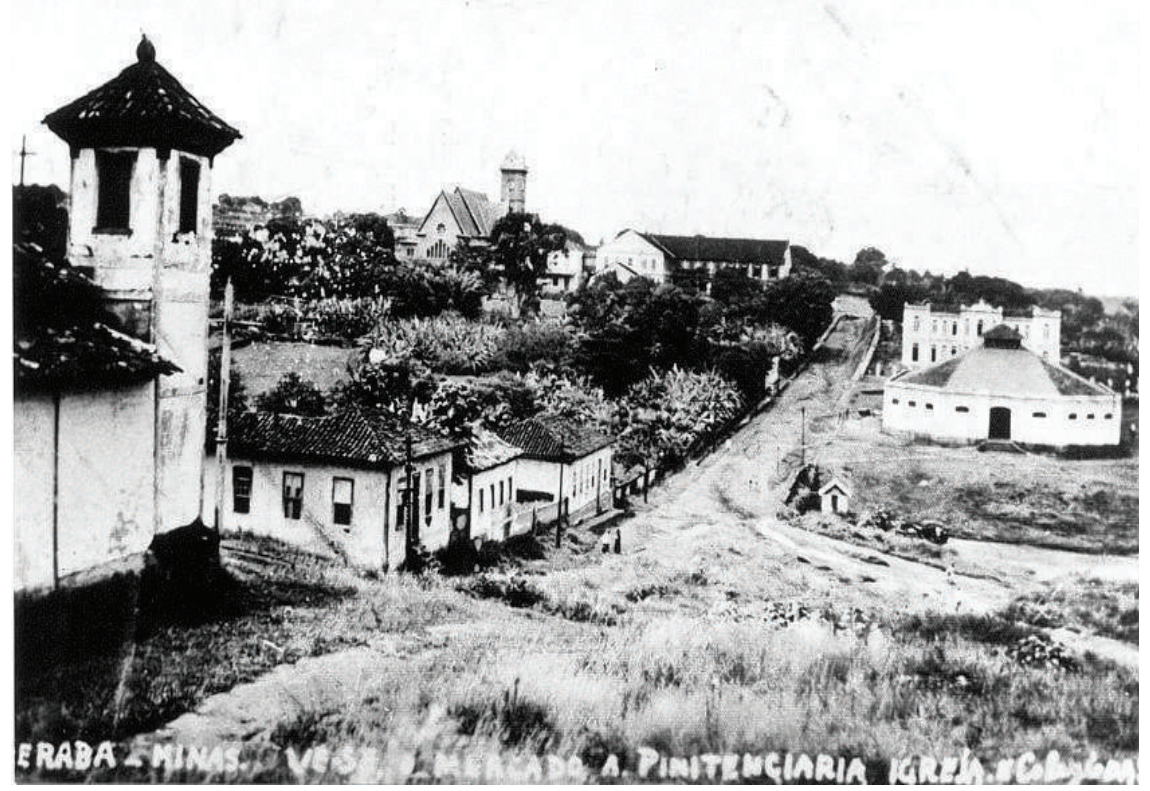

Fonte: APU

Todos esses espaços foram (re)significados ao longo do tempo, cada um detentor de especificidades e possibilitando a construção de identidades

\footnotetext{
${ }^{9}$ A Igreja Santa Rita foi construída em 1854 e, ao longo de sua história, passou por várias reformas, mantendo sua estrutura e arquitetura originais. Primeiro imóvel da região tombado pelo Instituto de Patrimônio Histórico e Artístico Nacional (1939), a igreja mantem celebrações religiosas e abriga o Museu de Arte Sacra com diversificado acervo de peças barrocas do século XIX e peças da cúria diocesana. O Mercado Municipal, prédio em forma de um octógono, construído em 1924 e tombado pelo Conselho do Patrimônio Histórico e Artístico de Uberaba em 1999 (Decreto 1903), é importante ponto de comércio e sociabilidade dos moradores da cidade. O prédio, que hoje abriga o Campus I da Universidade Federal do Triângulo Mineiro, foi construído em 1912, para abrigar a Penitenciária de Uberaba. Em 1954, a penitenciária foi desativada e no prédio doado para funcionamento do curso de Medicina da nascente faculdade da cidade e, em 1959, suas estruturas foram reformuladas para se tornar efetivamente a Faculdade de Medicina do Triângulo Mineiro, federalizada em 1960. o Colégio Nossa Senhora das Dores, em funcionamento desde 1895, foi criado pelas Irmãs Dominicanas, é um dos mais tradicionais colégios da cidade. A Igreja São Domingos, inaugurada em 1904, é a primeira igreja da ordem Dominicana a ser construída em todo o Brasil.
} 
sociais que desvelam como os homens se apropriam da realidade e transformam-na segundo suas necessidades e interesses. E nesse processo vão se formando diferentes memórias e também o patrimônio de uma coletividade. Frequentemente, a imagem que se divulga da cidade de Uberaba e que é aceita pela maioria de seus moradores, abarca essa região como significativa de sua história ao longo do tempo. São construções arquitetônicas e logradouros, são elementos da paisagem natural, ${ }^{10}$ são relações que lá se estabeleceram pois como aponta Salvadori, “o que se preserva não é uma 'coisa', mas um dado da cultura" ${ }^{11}$ que foi apropriado pelos sujeitos que o vivenciou e atribuiu sentidos.

Muitos desses sentidos estão guardados nas memórias e histórias dos moradores da cidade que, à medida que novas experiências são vividas, vão atribuindo novos sentidos e/ou suas lembranças vêm à tona ora em efusiva alegria, ora em ressentimento por aquilo que se considera perda. Os mais velhos ainda se recordam de tempos idos quando a concorrida matinê no elegante Teatro São Luiz, reunia jovens para o lazer e o footing na Praça Rui Barbosa após a sessão. Nessa ocasião, histórias de negócios, flertes e amizades.

A Praça Rui Barbosa ainda guarda memórias e histórias singulares. Alguns casarões estão em pé e são exemplares da riqueza auferida no início do século XX; sendo que alguns já foram demolidos, em nome do progresso, para construção de galeria comercial e estacionamento; o cinema, que durante décadas foi ponto de sociabilidade e elegância com a exibição de filmes e o footing das matinês está desativado e vive a incerteza da demolição ou preservação; a praça que a cada década, teve sua paisagem alterada, é ponto de passagem e não de sociabilidade. Ressalte-se que a cada nova administração, a praça passou por um tipo de alteração como indicativo das concepções e da memória que se queria legar. Possivelmente, muitos daqueles que diariamente circulam pela praça desconhecem sua importância histórica e/ou seu valor como patrimônio.

\footnotetext{
${ }^{10}$ Um dos elementos naturais mais significativos no Patrimônio de Uberaba é a árvore gameleira (Ficus adhatodifolia), árvore de grande porte e ampla copa, cujo nome é derivado de sua madeira, utilizada para fabricar gamelas. Em um dos trechos da Rua do Comércio, no final do século XIX, foi construída a Praça Crispiano Tavares e em um de seus lados foi plantada uma gameleira. De frondosa copa, a praça passou a ser cognominada popularmente Praça da Gameleira e sob sua sombra muitas histórias aconteceram porque era usual fazer piqueniques nos finais de semana ou mesmo encontrar amigos. Nos anos 1960, a árvore foi condenada devido ao apodrecimento de seu tronco. Na década seguinte, na então Praça Afonso Pena, foi construído um palco em forma de concha no afã de o lugar abrigar apresentações culturais. E ainda hoje não é raro as pessoas se referirem ao logradouro como Praça da Gameleira.
}

${ }^{11}$ SALVADORI, Maria Ângela B. História. Ensino e Patrimônio. Araraquara: Junqueira \&Marin, 2008. 
Na parte inferior da Praça Rui Barbosa, onde iniciava a Rua do Comércio, foi construído um calçadão com bancos para os transeuntes e lojas comerciais com seus ruidosos anúncios. Seguindo em frente, atravessa-se a Avenida Leopoldino de Oliveira e desse lado, ainda hoje, há marcas do comércio_dos imigrantes como as lojas de armarinhos. Ao chegar ao quinto quarteirão, uma ampla avenida e em seu centro a estátua de Zumbi como símbolo da resistência negra e que naquele lugar, existiu a Igreja do Rosário, demolida em 1924, sem muitas explicações das autoridades municipais. ${ }^{12} \mathrm{~A}$ duzentos metros acima, a Praça Comendador Quintino ou Praça do Grupo Brasil como ficou conhecida, mais lembranças latentes. O Grupo Escolar de Uberaba - ou simplesmente "Grupo Brasil" - é a primeira escola pública da cidade de Uberaba (1909). A edificação, em arquitetura moderna, figurou como ideia de construção de espaços próprios para a educação escolar que pudessem abrigar em um só prédio as escolas que estavam isoladas. Esses espaços de educação foram implantados sob o patrocínio do discurso da modernidade, para que simbolizassem e marcassem um tempo - pretensa e consideravelmente novo. O colégio era destinado ao ensino de alunos e alunas que cursavam o ensino primário. Porém, meninos e meninas estudavam em horários separados. Os estudantes possuíam aulas dos conteúdos científicos e também de atividades manuais como marcenaria para os meninos, e, confecções e bordados para as meninas. Gerações de meninos e meninas passaram pelos bancos escolares do Grupo Brasil, sendo que, atualmente, na escola, há alunos da quarta geração daqueles que lá estudaram no princípio do século XX. É possível encontrar, também, antigos alunos que ressentem de seus netos ou bisnetos não estudarem naquela que é a mais antiga escola da cidade e que guarda tantas histórias. Outros ressaltam a qualidade do ensino ali ministrado e a rigidez dos mestres que formaram tantos alunos, tanto sujeitos ilustres na comunidade, quantos anônimos.

Nas memórias e histórias da Praça Comendador Quintino e seu entorno, lembranças - quase épicas - das sessões do antigo Cine Capitólio e, posteriormente, Royal. Segundo antiga frequentadora do cinema, em seus dias de juventude - década de 1940 -, os filmes em cartaz no cinema mais popular da cidade - o preço do ingresso era mais barato que nos demais eram os mesmos do Cine Metrópole, este localizado na Avenida Leopoldino de Oliveira, próximo a Praça Rui Barbosa em prédio de arquitetura art déco e considerado o primeiro arranhacéu da região. Ao terminar a sessão no Cine

${ }^{12}$ A história da Igreja do Rosário, sua construção, suas relações com a comunidade uberabense e sua demolição ainda carecem de estudos históricos. 
Metrópole, um funcionário pegava os rolos de filme e corria, literalmente, até o Cine Royal (no alto do aclive) para que os ansiosos expectadores pudessem apreciar a exibição do filme. Para os sujeitos de menor poder aquisitivo, freqüentar o Cine Royal representava estar sintonizado com os modos de lazer daqueles de maior poder aquisitivo, mesmo que para isto a sessão fosse interrompida para aguardar que o funcionário chegasse com outro rolo de filme.

Igualmente, as festas juninas e quermesses no pátio da Igreja São Domingos, as procissões das igrejas daquelas imediações (Santa Rita, Rosário e São Domingos), as conversas nas portas das casas comerciais dos imigrantes. Enfim, são múltiplas memórias e histórias que colaboram na formação de uma identidade coletiva e de um patrimônio local.

De acordo com a Constituição Federal de 1988, artigo 216:

Constituem patrimônio cultural brasileiro os bens materiais de natureza material e imaterial, tomados individualmente ou em conjunto, portadores de referência à identidade, à ação, à memória dos diferentes grupos formadores da sociedade brasileira.

A essa definição estão incluídos os conjuntos urbanos e sítios de valor histórico e nessa categoria, classificamos os bens materiais de Uberaba aqui privilegiados. $\mathrm{Na}$ cidade há vários bens tombados pelo Conselho do Patrimônio Histórico e Artístico de Uberaba - CONPHAU, outros já inventariados e os bens materiais da área central, aqui abordados, concentram, em certa medida, os significados atribuídos por parcelas de grupos sociais como parte de um "script daquilo que é esperado que aconteça em seu futuro e das funções a desempenhar", ${ }^{13}$ porque representam uma fase considerada áurea na história da cidade, de seu poderio econômico e de destaque em toda a região do Triângulo Mineiro.

E ainda que muitos, na contemporaneidade, não os reconheçam como patrimônio a ser preservado, a institucionalização via tombamento ou inventário são estratégias para salvaguardar os bens da demolição ou modificação na fachada. Não é raro uma construção em processo de estudos para tombamento ser incendiada ou demolida e, em seu lugar, iniciar obras de um estacionamento ou um edifício de vários andares (residencial ou comercial). Por outro lado, o apagamento de memórias e de histórias pode ser aferido na

\footnotetext{
${ }^{13}$ CANANI, Aline Sapiezinskas K. B. "Herança, sacralidade e poder: sobre as diferentes categorias do patrimônio histórico e cultural no Brasil.” Horizontes Antropológicos. Porto Alegre, ano 11, n.23, jan/jun 2005. p.167.
} 
demolição de construções, na reestruturação do espaço. Parece haver uma obsessão pelo novo, uma busca incessante por símbolos que apontem um futuro diferente e superior a condição presente, sem perceber que a ignorância do patrimônio acarreta a perda das referências de uma coletividade.

Assim como vários bens patrimoniais subsistem, outros foram apagados seja em função de novas demandas ou de novas expectativas sociais e políticas, o que demonstra a tensão entre lembrança e esquecimento. Alguns bens parecem querer reafirmar a memória daquela que foi cidade primaz na região do Triângulo Mineiro e de lado oposto, o apagamento dos bens que não contribuíram para ratificar essa imagem ou à medida que se alteraram as representações, deixaram de atender aos propósitos de novos tempos.

Artigo recebido para publicação em 30/11/2012

Artigo aprovado para publicação em 31/05/2013 